Faculty of Human and Social Development

Faculty Publications

This is a post-review version of the following article:

CRC General Comment 7 Indicators Framework: A tool for monitoring the implementation of child rights in early childhood

Ziba Vaghri, Adem Arkadas, Sami Kruse and Clyde Hertzman

May 2011

The final publication is available at Taylor \& Francis Online via:

http://www.tandfonline.com/doi/full/10.1080/14754835.2011.568916

Citation for this paper:

Vaghri, Z., Arkadas, A., Kruse, S., \& Hertzman, C. (2011). CRC General Comment 7 Indicators Framework: $A$ tool for monitoring the implementation of child rights in early childhood. Journal of Human Rights, 10(2), 178-188. 


\title{
CRC General Comment 7 Indicators Framework: A Tool for Monitoring the Implementation of Child Rights in Early Childhood
}

\author{
ZIBA VAGHRI, ADEM ARKADAS, SAMI KRUSE, \\ AND CLYDE HERTZMAN
}

\begin{abstract}
United Nations Convention on the Rights of the Child (CRC) has universal recognition as the main human rights treaty providing international standards and a yardstick for fulfillment of children's rights. The Convention stipulates a monitoring system for countries that signed up to it. This system places international legal obligation on countries to write periodic reports to the Committee on the Rights of the Child (UNCRC) as the monitoring body of the Convention. The monitoring Committee on the Rights of the Child as a part of the Convention (Articles 42-45 of the CRC) also issues general comments to guide governments in better understanding, implementing, and monitoring the implementation of the Convention in their countries. Therefore, it provides a basis for developing child rights indicators. Its General Comment on implementing child rights in early childhood provides an excellent basis for developing early childhood indicators based on human rights. The manual and the framework developed is a tool to address concerns to better realize young children's rights through better data collection, analysis, monitoring, and reporting through provision of a structured guide to help governments to fulfill their obligation for state reporting and most importantly towards the youngest members and rights holders of their societies.
\end{abstract}

\section{Introduction}

Advances in science and technology have transformed the way we look at and think about early childhood. The existing knowledge in brain research, neurodevelopment, and genetics provides adequate evidence in support of the early years doctrine, which is marked by extremely rapid development of the brain and other key biological systems, and has a determining role in setting the tone of an individual's health for the remainder of one's life. ${ }^{1}$ Additionally, economists have presented a scientific basis for prevailing theories concerning the multiple rates of return that investments in early childhood development (ECD) provide and have also illustrated that these investments can push a society towards to a prosperous future with healthy citizens.

Along with researchers and academics, politicians and policymakers have become aware of the significance of the early years in societies' health and productivity. While the awareness that early experiences have a key role in the health outcomes of later life, as well as impact the overall health of society, science further elucidates how the quality of children's environments greatly impact their early experiences and shapes their health outcomes (Irwin, Siddiqi, and Hertzman 2007). These environments include everything 


\section{Ziba Vaghri et al.}

from the most proximal, for example, his or her family unit, to the most distal such as the international environment. In consideration of this key information, safeguarding measures have to be taken at the level of all of these environments to assure the quality of the early years' experiences. One such measure is adopting a rights-based approach to ECD interventions as legally and politically grounded in international human rights instruments and their monitoring bodies.

\section{Rights in Early Childhood}

Human rights are an intrinsic prerogative of all human beings independent of the environment surrounding them (Chapman 1993). Young children, due to their special needs for their survival and development, require extra attention to their early environments. Therefore, despite the above mentioned concept that rights exist independent of environments, fulfillment of young children's rights cannot be separated from the nature of the environments in which they grow up, live and learn. As a result, a universal safeguarding system is required to guarantee the realization of young children's rights in countries across the globe.

The United Nations (UN) Convention on the Rights of the Child (CRC or the Convention), as adopted in 1989, and its monitoring body, the United Nations Committee on the Rights of the Child (the Committee or UNCRC), form the universal safeguarding system. Ratified by 193 countries around the world, CRC is the most widely agreed upon international human rights instrument in the world and can thus provide a legal guarantee to respect, to protect, and to fulfill the civil and political as well as economic, social, and cultural rights of early childhood (which is defined by the Committee as a period below 8 years of age). ${ }^{2}$ The Convention establishes a monitoring body overseeing a system of regular state reporting and guidance in the form of General Comments on the implementation of the CRC as authoritative interpretations of the provisions in the CRC (UNCRC 1989: Articles 43-45).

\section{Monitoring the Implementation of Child Rights in Early Childhood}

The Convention is not only the most widely ratified international human rights instrument but it also overcomes the ideological divide on human rights as it links civil and political rights with economic, social, and cultural rights. As economic, social, and cultural rights are subject to progressive realization, the economic and social rights enshrined in the CRC are subject to progressive realization as well. This means that what is expected of a state to fulfill its CRC obligations towards young children will differ over time. With a view to monitoring progress in the realization of child rights in early childhood, a state needs a tool to measure this variable dimension. The UNCRC in its General Comment 7 (GC7) suggests that indicators and benchmarks should be used by state parties to monitor the realization of child rights in early childhood (UNCRC 2005: para. 39). Therefore, child rights indicators of early childhood should derive from GC7 since it provides the normative framework for the indicators needed to monitor the implementation of the CRC with a view to holding duty bearers accountable (Hunt 2003).

The United Nations Development Programme's (UNDP) Human Development Report 2000: Human Rights and Human Development states that indictors "are powerful tools in the struggle for human rights. They make it possible for people and organizations-from grassroots activists and civil society to governments and the United Nations - to identify important actors and hold them accountable for their actions." It adds, "they can be used as tools for: 
- Making better policies and monitoring progress;

- Identifying unintended impacts of laws, policies and practices;

- Identifying which actors are having an impact on the realization of rights;

- Revealing whether the obligations of these actors are being met;

- Giving early warning of potential violations, prompting preventive action;

- Enhancing social consensus on difficult tradeoffs to be made in the face of resource constraints;

- Exposing issues that had been neglected or silenced.

Crucially, human rights indicators can help States, and others, recognize when national and international policy adjustments are required" (Hunt 2003: 6).

At this, one has to ask two basic questions: What is monitoring and why is it so important and germane to the realization of the CRC? Monitoring "is a broad term describing the active collection, verification and immediate use of information to address human rights problems. The term includes evaluative activities at the UN headquarters, as well as first hand fact gathering at country level" (CRIN-NGO 2005). ${ }^{3}$

In light of this definition, it is important to note that "State parties" to the Convention are under an international legal obligation to submit periodic reports to the UNCRC on the progress and implementation of the Convention within their states (Article 44). The Committee also has the prerogative, under the Convention (Article 45d), to guide governments to implement and to report on the implementation of children's rights properly. The Committee has thus far adopted 12 General Comments for these purposes. ${ }^{4}$

One of these is "General Comment 7: Implementing Rights in Early Childhood" (UNCRC 2005). It was drafted and adopted in response to the observation by the UNCRC that young children under the age of eight were often entirely overlooked in state parties' reports of progress at implementing the CRC. The implication of this is that state parties have often neglected their obligations towards young children, regarding them more as objects of care and need than as rights bearers and active social participants. While GC7 represents authoritative guidance to state parties in fulfilling their CRC obligations to young children, without a corresponding operationalized framework of indicators, GC7 has very limited practical value and, as a result, has remained underutilized.

At this point, one needs to ask a set of questions as to how rights in texts can be transferred into rights in practice. How do transnational ideas such as human rights approaches to child development become meaningful in local social settings? How do they move across the gap between an international awareness of human rights and local sociocultural understandings about children and childhood? Is the status of treaty ratification alone a good indicator of the realization of a right? The existing evidence indicates no consistent associations between ratification of human rights treaties and health or social outcomes (Palmer et al. 2009). What seems to be the problem? Why can't these treaties, prepared with good intentions and based on a sound knowledge base, be conducive to improved rights status? What are the obstacles? Does the problem stem from the gap between theory and practice, or is the problem due to a lack of tools sensitive enough to detect and measure relevant change and progressive realization of child rights in early childhood? With respect to the former problem, stringent requirements for ratification of treaties, improved accountability mechanisms to monitor compliance of states with treaty obligations, and financial assistance to support the realization of the right could be a part of the solution. As to the latter problem, we are hopeful that the development of a tool to assist with monitoring the realization of young children's rights and identifying and understanding the areas in which 
progress has been made, could be very helpful in an environment of good faith. ${ }^{5}$ We have undertaken several initiatives that strive to test these propositions.

In 2006, we, (a group of researchers, several officials from the WHO and UNICEF, as well as child rights advocates from several nongovernmental organizations) approached the UNCRC stating that GC7, despite being a comprehensive document prepared with insight and good intentions, remains theoretical. We proposed that to enhance its utility it would be helpful to develop a simple set of practical indicators. After a year of deliberation, the Committee sent letters of invitations to the group members requesting them to collaborate on a framework of indicators based on GC7. As a result, the Early Childhood Rights Indicators Group (GC7 Indicators Group) was formed. The group sought to address the issues by creating a monitoring tool comprised of sets of indicators that state parties could use to assess the rights environment and the implementation of rights in early childhood in their countries as part of their reporting obligation to the UNCRC.

The framework, which was completed in May 2008, addresses the same underlying and cross-cutting themes that are elaborated in GC7. General Comment 7 addresses the specific rights that are upheld in the CRC while keeping in mind the need to recognize young children as rights holders and active social participants, state parties' obligations to provide appropriate and adequate support for caregivers of young children, the need for integrated service provision in support of holistic approaches to child development, the need to support and empower the evolving capacities of young children, empowering and positive education, preschool, and play experiences, freedom from social exclusion by virtue of young age, gender, race, disability etc., freedom from violence, and understanding of the particular vulnerability of young children.

\section{Organizational Framework of the Indicators}

The basic objective in developing this framework was to adopt a structured and consistent approach for translating CRC standards into indicators that are contextually relevant and useful at a country level. The indicator framework includes 15 indicator sets that are based on existing UNICEF and health indicators but also proposes new configurations of administrative data that could be used to gauge the implementation and enjoyment of rights in early childhood. These indicators are arranged within a hybrid model that combines elements from the structure of the CRC reporting guidelines, the format of UNICEF's Multiple Information Cluster Surveys, and the structure of the World Health Organization's Right to Health framework.

The indicator sets proposed in the framework are organized according to the clusters of the UNCRC Reporting Guidelines (UNCRC 1991). Under each cluster heading there is a rationale for the indicator sets. As for the framework, to be conceptually meaningful, it should be anchored in the normative content of the right, as enumerated in the relevant articles of the treaties and general comments of the Committee (United Nations Office of High Commissioner for Human Rights) (UN OHCHR 2008). For each indicator we have made appropriate references to relevant articles in the CRC and paragraphs of GC7. An overarching key question is also given in each rationale, which provides the foundation for the indicator (Vaghri et al. 2009). Following rationale statements, there is a table in which each foundational question is unpacked into sets of questions that are divided into sections titled: "Structure," "Process," and "Outcomes."

Structure, as an indication of commitment to take action, refers to the existence of institutions and policies aligned with the $\mathrm{CRC}$ and the realization of the particular rights 


\section{CRC GC7 Indicators Framework}

in question. Process refers generally to efforts made and actions taken following commitment and thus to specific activities, resources, and/or initiatives undertaken in pursuit of rights realization. Outcome refers to a resultant and measurable change either in the rights environment or in early childhood development measures. This three-tiered categorization was chosen with a view to reflect an emerging consensus on human rights indicators (Hunt 2003 and OHCHR 2008) and to facilitate easy convergence with UN human rights indicator efforts.

Within each table, we identify potential sources of information and propose one or two measures, which may be the most effective and parsimonious ways to describe the specific achievement with regard to the rights under consideration. Within each table, we also delineate the relevant duty bearers and provide references to sections of the "Reporting Guidelines."

The GC7 Indicators Framework was finalized in early 2008 and presented to the UNCRC. The Committee was pleased with the work and the proposed indicators and encouraged the group to run pilot studies in several countries. Over the last year the Early Childhood Indicators Group has worked on developing an implementation manual for these indicators. The following sections will provide information on the implementation manual. The group has also mapped out six countries - two from each income level (low, medium, and high income) - to pilot the manual. The group conducted the first pilot study in Tanzania in the fall of 2009.

\section{The Manual for Child Rights Indicators in Early Childhood}

The group has developed an implementation manual for the framework to further enhance the usability of the indicators (Vaghri et al. 2009). This implementation manual is an easyto-follow and user friendly guide that will help the state parties assess whether the rights of young children are being upheld in their jurisdictions. It promotes better data collection, more careful analysis of data, more complete monitoring, and, as a result, a much more comprehensive reporting of the implementation of child rights in early childhood. In short, it is not only a tool for governments to fulfill their obligation of periodic reporting to the UNCRC in a very descriptive and thorough manner but it is also an efficient institutional self-assessment tool and an inventory checklist for state parties to become aware of what is already there and what needs to be there, in terms of policies and programs, to facilitate the realization of the Convention on the Rights of the Child for early years.

The manual is written with a view to being concise, clear, and understandable, to include examples and checklists for each set of indicators, to employ a rights language, to provide knowledge, practice, and coverage, and to provide examples of written policies in the form of policy papers. Similar to the indicators framework, the manual is based on the Committee on the Rights of the Child's structured reporting guidelines. Each one of the 15 indicator sets in the manual contains a flowchart that is anticipated to be the focal point as it walks the reader through the indicator questions and provides the reader with good practice resources and suggestions for each question.

Recognizing the need to capture a duty bearer's commitment, efforts, and results, the group adopted the structure, process, and outcome model for each indicator flowchart in an attempt to bring each attribute of the child right to the fore and to assess the steps taken by the states parties to meet their obligations in that respect.

The flowchart begins with a series of questions about existing policies and programs. This enables the state party to measure its commitment as the main duty bearer to the relevant child rights standard, followed by process, to measure efforts undertaken to reach 

a particular commitment and the results of those efforts over time (usually since the last periodic report).

The indicator flowchart ends with outcomes defined as any change in the environment of that given right or in the state of the early child development as measured by valid indicators. In cases where the country's answer to a given policy/program question is negative the flowchart provides examples of model policies/programs from countries across the globe. A conscious attempt has been made to include as many examples from resource poor countries as possible. These examples are often followed by Web site addresses or additional information.

It is assumed that upon completion of CRC reports that governments would have a fairly good idea about the existing gaps in their systems. These examples of policies/programs,

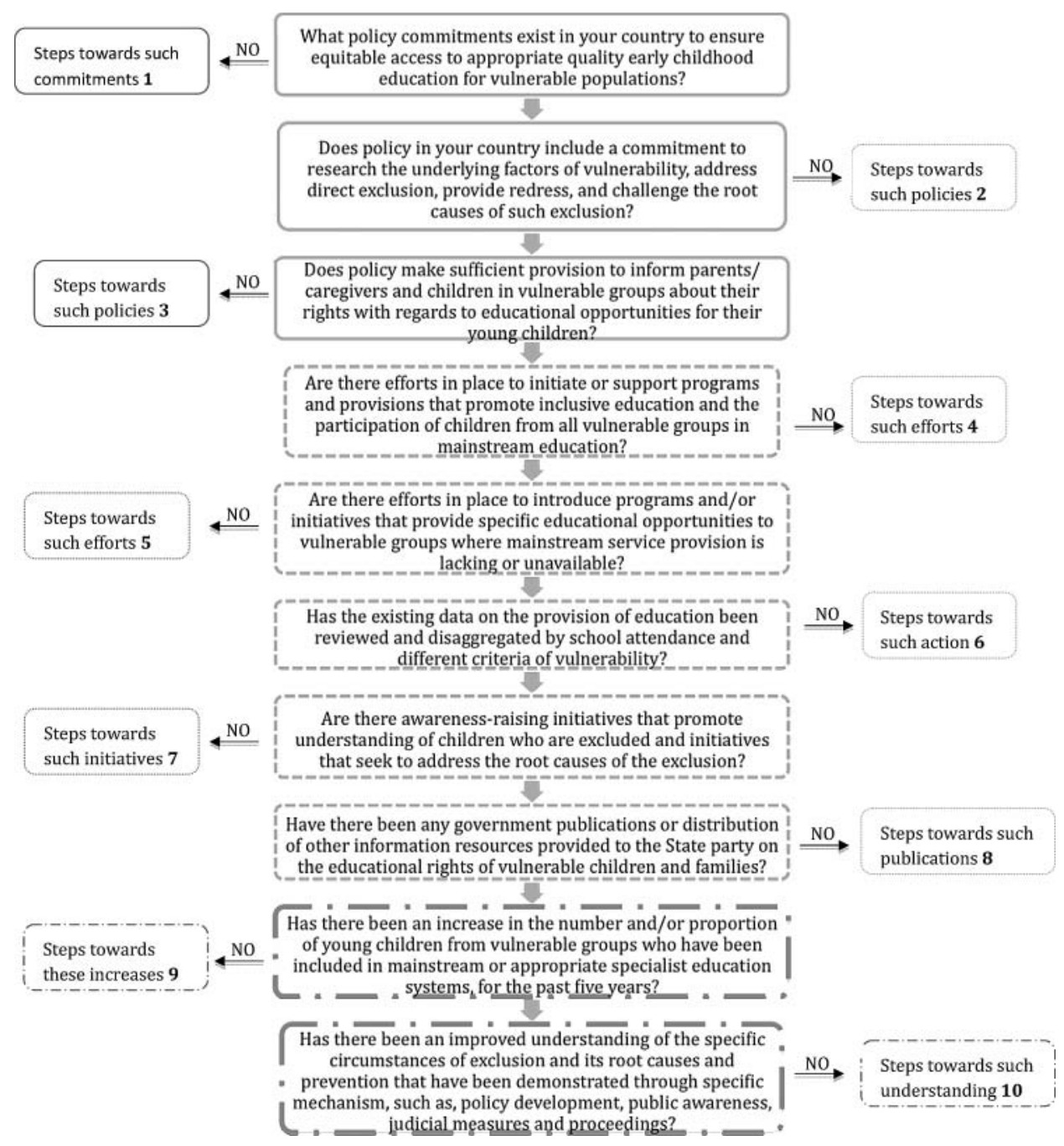

FIGURE 1. Schematic presentation of some steps to verify the presence of structure, process, and outcome for Indicator Set 12: Educational Provision for Vulnerable and Excluded Young Children (Vaghri et al. 2009). 
and the additional information, are meant to serve as a strong starting point for governments in their journey to fill in the existing gaps in their systems. Figure 1 depicts the flowchart for Indicator Set 12, "The Right to Educational Service Provision for Vulnerable and Excluded Young Children" and Table 1 provides a sample indicator set.

\section{Contextual Relevance of Indicators}

Contextual relevance is a key consideration in the acceptability and use of indicators among potential report writers. Countries often differ in terms of their level of development and realization of human rights. As a result of these differences, the nature of institutions, the policies, and the priorities of the state may differ. Therefore, it may not always be possible to have a set of universal indicators to assess the realization of child rights.

Keeping countries' variations in mind, when designing the indicators, the GC7 Indicators Group felt that there might be a need to customize certain parts of the indicator sets. Moreover, in 2008 upon presentation of the framework to the UNCRC, through a strong letter of support sent to the GC7 Indicators Group, the Committee articulated that it

... welcomes the plans to finalize this project so that a set of broadly applicable indicators regarding the implementation of rights of young children becomes available. The next steps have to be pilot studies in order to test and revise the list of indicators if necessary... (OHCHR 2008b)

\section{Pilot Testing}

The first pilot, conducted in 2009 in Tanzania and provided the opportunity to see the indicators at work in the context of a low-income country, recognizes general areas of ambiguity in the manual as well as identifies specific concerns that arose. The pilot managed to fulfill these objectives through the combined effort of an in-country task force and the project team. Additionally, it became clear that creating an electronic version of the indicators could be an effective step forward that would not only reduce the time required to make the countries' periodical reports but could also ultimately change the method of report submission to UNCRC.

Through piloting, we learned that, although the information gathered through the indictors are in simple and quantified form, there is a need for the indicators to be described and reviewed in a qualitative manner as well. Simplification (or reductionism) is one of the distinct characteristics and main appeals of indicators (Merry 2009); however, caution needs to be taken when making comparisons within the context of countries where the outcome data does not exist. In a numerical form, knowledge carries a distinctive authority. It is, however, essential that the outcome data exist and are reported as it is only then that this information can make powerful and valid statements. The issue of missing outcome data, which is common in countries with limited resources, can create a false picture out of the collected information by the indicators and can risk the hazard of wrong conclusions in the CRC reporting process.

Data collection is a process that is often somewhat constrained everywhere. While the most obvious reason for this is usually the cost of data collection, sometimes the concerns about what data reveals is the underlying reason for the missing data (Davis, Kingsbury, and Merry 2009). For example, disaggregating information collected through household surveys can reveal information on many aspects of households. Some of this information 
Table 1

Suggestions Box for Indicator Set 12: Right to Educational Service Provision for Vulnerable and Excluded Young Children ${ }^{6}$

1. Develop policies that support social inclusion and insure equitable access to education, such as policies that

a. abolish school fees

b. provide income support to poor and rural households to reduce reliance on child labor

c. promote teaching in children's mother tongue

d. promote educational opportunities for disabled children and children affected by HIV/AIDS.

For example, see the European Union National Strategy reports for social protection and social inclusion: http://ec.europa.eu/employment_social/spsi/strategy_reports_en. htm.

2. Develop policies that support a commitment to research. The Encyclopedia of Early Childhood Development Web site provides multiple examples of international research initiatives: http://www.child-encyclopedia.com/en-ca/recherche.html?q=research.

3. Expand on policies that make provisions to inform parents and children from vulnerable or excluded populations about their rights with regard to educational opportunity. For example, educational quotas for children from vulnerable or excluded populations, such as indigenous or minorities (Maasai, Hadzabe/Hadza, Ndorobo, Barabaig, Iraqw, Mbulu and others in Africa, First Nation in Canada, Aborigine in Australia, Roma children in Europe), children of traveller or nomad families, children living with mental/physical disabilities, albino children, girl child, children living/working on the streets, children living with HIV/AIDS and so on.

4. Advocate for programs that encourage inclusive education and participation of children from all vulnerable groups in mainstream education. The National Inclusive Education Awareness campaign in Canada Web site offer examples of multiple awareness-raising initiatives: http://www.inclusiveeducation.ca.

5. Encourage and implement programs that provide specific educational opportunities to vulnerable groups. For examples on educational programmes for vulnerable populations, see:

UNICEF Educational Priority Areas project: http://www.unicef.org/ romania/education_1617.htmlAga Khan Foundation Madrasa Early Childhood Education Programme: http://partnershipsinaction.org/work/focus _ education.php

Public Health Agency of Canada's Aboriginal Head Start Program: http://www.phacaspc.gc.ca/dca-dea/programs-mes/ahs_main-eng.php

6. Work with university-based researchers and data managers to improve data resources.

7. Create awareness-raising campaigns, for example the "Leave No Child Out" Campaign: http://www.unicef.org/ceecis/kids_6643.html.

8. Work with UN offices (such as WHO, UNICEF, UNESCO, UNDP) in your country to develop publications, to translate relevant information into local languages, as well as carry out research from within your country to publish information on educational rights for vulnerable children and families. For guidance materials, see

A Human Rights Based Approach to Education for All: http://www.unicef. org/publications/files/A Human Rights _Based_Approach_to_Education for_All.pdf 
Table 1

Suggestions Box for Indicator Set 12: Right to Educational Service Provision for Vulnerable and Excluded Young Children ${ }^{6}$ (Continued)

Poverty Reduction Begins With Children: http://www.unicef.org/publications/files/ pub poverty reduction en.pdf

9. Create a monitoring and evaluation system based on existing international studies.

10. Explore the lack of improvement through, evaluation of policies, judicial measures and proceedings, and also conduct focus groups or investigate by using questionnaires.

\section{Other reference tools}

Encyclopedia of Early Childhood Development: http://www.child-encyclopedia.com/ en-ca/home.html

UNESCO, Education for All—Global Monitoring Report: http://www.unesco.org/en/ efareport/reports/2007-early-childhood/

may be sensitive, especially when considered in the cultural context in which it is collected. For example, the age of the female head of the household or age at the time of child bearing can shed light on the prevalence of issues such as child brides. A UN study found that between 1995 and 2003, 85 countries or areas reported information on the number of first marriages by age of bride and groom, representing 27 percent of the world population. None of the 50 least developed countries provided this data to the United Nations (UN DESA 2006: 11, 18-19). Undoubtedly, this data deficit inhibits evaluating the extent of child marriage in the areas where this practice is common and also worldwide.

Whether a lack of outcome data is due to a lack of resources or stems out of a desire to avoid shining the spotlight on the further information that particular data may reveal, the indicators can help highlight the lack of data-gathering capacity in a particular country. The long-term benefit of this is that the process will help accentuate data collection as an area to improve during the time between the two periodical reports sent to UNCRC.

Through the piloting process, it became clear that adapting the indicators and manual into an electronic version could be an effective step forward. This would not only reduce the time required to make the countries' periodical reports but could also ultimately change the method of report submission to UNCRC.

\section{Conclusion}

Children of all ages have inherent human rights that are enshrined in the international human rights normative framework. For different age groups, these rights are exercised by their holders and should be upheld by duty bearers. Young children have equal rights and freedoms. Young children have specific vulnerabilities and needs that require special consideration with respect to the realization and exercise of their rights. Governments are under international legal obligation to respect, to protect, and to fulfill early childhood rights without delay as the early childhood period spanning from prenatal to age eight is a specific period when changes in the emotional, intellectual, social, and physical development of young children lay the foundations of human development and subsequently the social and economic development of societies. This is especially true as early child development is one of the strong determinants of the health and productivity of any society. 
The Convention on the Right of the Child is the most widely accepted and legally binding human rights treaty that provides a framework for governments with a rightsoriented approach to child development. Despite the existence of strong and clear guidelines, over the years, the task of monitoring CRC implementation in early childhood has remained a challenge, in part due to a lack of monitoring tools. With the advent of GC7 and the GC7 Indicator Framework, rights in early childhood no longer need to remain a mystery or invisible. The GC7 Indicators Group has now developed a comprehensive guideline with indicators by which the enjoyment of rights and the rights environment of the world's youngest and most vulnerable citizens can be understood and monitored. Field testing the GC7 Indicator Framework and the Manual is an essential step toward building an internationally recognized child rights monitoring tool. It is our belief that upon pilot testing, the global deployment of such a tool will result in building efficient child rights monitoring systems for young children in countries across the world.

\section{Notes}

1. See, for example, The Lancet "Child Development in Developing Countries" series at http:// www.who.int/child_adolescent health/documents/lancet shild development/en/index.html (accessed on 5 January 2010).

2. See Paragraph 4 of the Committee's General Comment 7 "Implementing Child Rights in Early Childhood" for the definition of early childhood.

3. Adaptation of the "monitoring" definition of the University of Minnesota, Human Rights Library at http://www1.umn.edu/humanrts/monitoring/chapter1.html\#D2 (accessed on 25 August 2009).

4. All general comments can be found at http://www2.ohchr.org/english/bodies/crc/comments.htm.

5. International law stipulates that laws are implemented in good faith (Pacta sunt servanda) under the Article 26 of the Vienna Convention on the Law of Treaties, 1969.

6. Vaghri et al. 2009.

\section{References}

CHAPMAN, Audrey R. (1993) Exploring a Human Rights Approach to Health Care Reform (Washington, DC: American Association for the Advancement of Science).

CHILD RIGHTS INFORMATION NETWORK-NGO GROUP FOR THE CONVENTION ON THE RIGHTS OF THE CHILD (CRIN-NGO). (2005) The Use of Concluding Observations for Monitoring the Implementation of the Convention on the Rights of the Child: The Experiences of NGO Coalitions in Nine Country Case Studies. CRIN-NGO Group Joint Working Paper No. 2. (Geneva: NGO Group for the CRC; UK: Save the Children).

DAVIS, Kevin E., KINGSBURY, Benedict, and MERRY, Sally Engle. (2010) Indicators as a Technology of Global Governance. New York University Law and Economics Working Papers. Paper 212. [Online]. Available: http://lsr.nellco.org/nyu lewp/212 [7 April 2011].

HUNT, Paul. (2003) Right to Health Indicators: An Incremental Approach in Interim Report of the Special Rapporteur of the UN Commission on Human Rights on the Right of Everyone to Enjoy the Highest Attainable Standard of Physical and Mental Health. [Online]. Available: http:// www2.ohchr.org/english/issues/health/right/issues.htm [5 January 2010].

IRWIN, Irwin L., SIDDIQI, Arjuman A., and HERTZMAN, Clyde C. (2007) Early Child Development: A Powerful Equalizer (The final report submitted to the World Health Organization). [Online]. Available: http://www.earlylearning.ubc.ca/globalknowledgehub/documents/ WHOECD Final Report.pdf [5 January 2010].

PALMER, Alexis, TOMKINSON, Jocelyn, PHUNG, Charlene, FORD, Nathan, JOFFRES, Michel, FERNANDES, Kimberly, et al. (2009) Does ratification of human rights treaties have effects on population health? The Lancet, 373(9679), 1987-1992. 


\section{Ziba Vaghri et al.}

UNITED NATIONS COMMITTEE ON THE RIGHTS OF THE CHILD (UNCRC). (2005) General Comment No. 7 Implementing Child Rights in Early Childhood. [Online]. Available: http://www2.ohchr.org/english/bodies/crc/docs/AdvanceVersions/GeneralComment7Rev1.pdf [5 January 2010].

UNITED NATIONS CONVENTION ON THE RIGHTS OF THE CHILD (UNCRC). (1989) [Online]. Available: http://www2.ohchr.org/english/law/crc.htm [25 October 2010].

UNITED NATIONS CONVENTION ON THE RIGHTS OF THE CHILD (UNCRC). (1991) General Guidelines Regarding the Form and Content of Initial Reports to be Submitted by State Parties under Article 44, Paragraph 1 (a) of the Convention (adopted by the Committee on the Rights of the Child at its 22nd meeting on 15 October 1991).

UNITED NATIONS DEPARTMENT OF ECONOMIC AND SOCIAL AFFAIRS (UN DESA). (2006) The World's Women 2005: Progress in Statistics (New York: United Nations).

UNITED NATIONS DEVELOPMENT PROGRAMME (UNDP). (2000) Human Development Report 2000: Human Rights and Human Development (New York: UNDP).

UNITED NATIONS OFFICE OF HIGH COMMISSIONER FOR HUMAN RIGHTS (OHCHR). (2008a) Report on Indicators for Promoting and Monitoring the Implementation of Human Rights. Seventh Inter-Committee Meeting of the Human Rights Treaty Bodies. [Online]. Available: http://www2.ohchr.org/english/bodies/icm-mc/docs/HRI.MC.2008.3EN.pdf [5 January 2010].

UNITED NATIONS OFFICE OF HIGH COMMISSIONER FOR HUMAN RIGHTS (OHCHR). (2008b). Letter dated July 20, 2008 from Yanghee Lee, Chairperson, Committee on the Rights of the Child, to Members of the GC7 Indicators Group, Dr. Clyde Hertzman and Dr. Ziba Vaghri, Human Early Learning Partnership, The University of British Columbia.

VAGHRI, Ziba, ARKADAS, Adem, ARNOLD, Caroline, HERTZMAN, Clyde, KIKUCHI-WHITE, Alan, CABRAL DE MELLO, Meena, et al. (2009) Manual on Implementing Early Childhood Rights Indicators Framework. [Online]. Available: http://content.yudu.com/Library/ A1nitv/ChildRightsIndicator/ 